www.jmscr.igmpublication.org Impact Factor 5.244

Index Copernicus Value: 5.88 ISSN (e)-2347-176x ISSN (p) 2455-0450 crossref DOI:_http://dx.doi.org/10.18535/jmscr/v4i5.28

Journal Of Medical Science And Clinical Research

\title{
ICTP as a Diagnostic Marker of Bone Resorption and Its Relation to Disease Progression and Treatment Response in Multiple Myeloma
}

\author{
Authors \\ Salwa Saad Khoudair ${ }^{1}$, Gehan Mostafa Hamed ${ }^{2}$ \\ ${ }^{1}$ MD Clinical Pathology, Professor of Clinical Pathology, Clinical Pathology Dept, Ain Shams University \\ ${ }^{2}$ MD Clinical Pathology, Lecturer of Clinical Pathology, Clinical Pathology Dept, Ain Shams University \\ Corresponding Author \\ Gehan Mostafa Hamed \\ 67 El Nasr St, Sheraton Heliopolis, Cairo, Egypt \\ Email: gehanzeina@yahoo.com Mobile no.:0020201224954542
}

\begin{abstract}
Aim: To assess the significance of collagen type I carboxy terminal telopeptide (ICTP) as a diagnostic marker of osteolysis, as well as its relation to disease progression and response to treatment in multiple myeloma (MM).

Subject and methods: ICTP was measured in 40 newly diagnosed MM patients (including 22 patients with osteolytic lesion), and 20 age-and sex-matched controls. Patients were followed up for detection of their response to treatment.

Results: The median and IQR levels of ICTP were significantly elevated in MM patients compared with controls $(0.65$ [0.15-0.8] $\mathrm{ng} / \mathrm{mL}$ versus 0.05 [0.04-0.07] $\mathrm{ng} / \mathrm{mL}, p<0.001)$, with significant higher median levels among patients with osteolytic lesion compared with myeloma patients without osteolytic lesion $(0.7$ [0.65 - 1.0$] \mathrm{ng} / \mathrm{mL}$ versus 0.1 [0.1 -0.2] ng/mL, $p<0.001$ ). According to ROC curve analysis, ICTP at a cutoff $0.3 \mathrm{ng} / \mathrm{mL}$ could detect osteolytic lesion with high sensitivity and specificity. ICTP was positively correlated with markers of renal impairment, hypercalcemia, anemia, thrombocytopenia and poor prognostic factors; lactate dehydrogenase $(\mathrm{LDH}), \mathrm{C}$ reactive protein $(C R P)$, hypoalbuminaemia, and $\beta 2$-microglobulin $(\beta 2 M)(p<0.05)$. Using logistic regression analysis, ICTP was found to be a significant predictor of osteolysis. Moreover, initial ICTP levels were higher in progressive/relapsed myeloma patients compared with responsive/stable patients $(p<0.001)$.

Conclusion: We suggest that ICTP is a reliable marker that can be used in the diagnosis and prediction of osteolytic lesion and prediction of treatment response in MM.

Key words: Multiple myeloma, ICTP, osteolytic marker, disease progression, response to treatment.
\end{abstract}

\section{Introduction}

Multiple myeloma (MM) is a plasma cell dyscrasia that accounts for approximately $1-2 \%$ of all cancers, $10-15 \%$ of all hematological malignancies and causes $20 \%$ of deaths from hematologic malignancies ${ }^{[1]}$. Mounting evidence indicates that the bone marrow (BM) microenvironment of tumor cells has a pivotal role in myeloma pathogenesis ${ }^{[2]}$. This interaction between MM cells and the microenvironment not only favors tumor growth but is also responsible for final myeloma portrait.

Bone disease is one of the hallmarks of MM; at diagnosis, approximately $80 \%$ of patients present with abnormal bone structure and during disease progression a large proportion of patients will 
develop osteolytic lesions ${ }^{[3]}$. Multiple myeloma bone disease not only results in a reduced quality of life due to pain, pathological fractures, or symptomatic hypercalcaemia; but may also be the deciding factor that determines if a patient requires anti-myeloma treatment. That is why proper diagnosis of osteolytic lesion is of great importance in $\mathrm{MM}^{[4]}$.

Osteolysis is mediated by an imbalance between osteoclast activity (increased) and osteoblast activity (decreased). Adhesion of MM cells to stromal cells induces the secretion of osteoclast activating factors such as tumor necrosis factor- $\alpha$ (TNF- $\alpha$ ), interleukin- 6 (IL-6), interleukin- 1 (IL1), matrix metalloproteinases, hepatocyte growth factors, parathyroid hormone - related protein, receptor activator of nuclear factor- $\mathrm{\beta} \beta$ ligand (RANK- L), vascular endothelial growth factor (VEGF), insulin growth factor (IGF) and macrophage inflammatory protein (MIP) - 1. In addition to the marked osteoclast activation, there is inhibition of osteoblast function. Myeloma cells produce dickkopf (DKK1), which inhibits the wingless-type MMTV integration site family member (WNT) pathway, and a soluble WNT inhibitor (sFRP-2) that suppresses osteoblast differentiation. The WNT signaling pathway is critical for osteoblast differentiation and the differentiation of mesenchymal stem cell into mature bone- forming osteoblasts ${ }^{[5]}$.

Conventional radiography has for many years been the standard method for the diagnosis of myeloma bone disease. This modality, however, suffers from a low sensitivity, since $30 \%$ of the trabecular bone mass must be absent for a lesion to become detectable. Magnetic resonance imaging (MRI) can increase the sensitivity at the cost of higher radiation exposure. Both modalities, however, only provide static information concerning the accumulated bone disease ${ }^{[6]}$

Biochemical markers of bone turnover can provide dynamic information concerning the velocity of bone turn-over at any given time point, and can be measured from either blood or urine samples. Furthermore, bone formation and bone resorption can be evaluated separately ${ }^{[7]}$. The extracellular bone matrix consists of collagens combined with various non-collagenous glycoproteins and proteoglycans. Type I collagen is the major extracellular matrix component in skin, soft tissue and bone, where it forms approximately $90 \%$ of the organic matrix ${ }^{[8]}$. When type I collagen is degraded, several different fragments including carboxy terminal telopeptide (ICTP) are formed and released into the circulation as stable fragment ${ }^{[9,10]}$. Serum ICTP is released from cathepsin K mediated proteolytic degradation of the chain $\mathrm{C}$ telopeptide of type 1 collagen during osteoclastic resorption, levels of which are supposed to reflect changes in the extracellular matrix representing new biochemical bone resorption marker ${ }^{[11]}$.

Despite the potential interest of the biochemical markers of bone turnover they are not used in everyday practice, and their usefulness to detect progressive osteolysis in relapsing patients or prediction of response to treatment has not been widely studied. Therefore, this study aimed to assess the significance of ICTP as a diagnostic marker and predictor of osteolysis in MM patients, as well as its relation to disease progression and response to treatment.

\section{Subjects and methods}

This study was conducted at Ain Shams University Hospitals on 40 newly diagnosed MM patients and 20 age-and sex-matched healthy controls for evaluation of ICTP level. An informed consent was taken from all participants before enrollment. The study design was approved by Ain Shams University Hospital Ethical Committee.

\section{Initial assessment}

All patients were subjected to full detailed history and careful clinical examination laying stress on presence of bone ache, pathological fractures, and manifestations of anemia, thrombocytopenia, hypercalcemia, hyperviscosity, and renal impairment. Complete radiological skeletal survey to detect pathological fractures, osteolytic lesion and osteoporosis. 
Laboratory investigations included complete blood count (CBC) using Coulter LH 750 cell counter (Coulter Electronics, Hialeah, FL, USA), examination of leishman stained peripheral blood (PB) and bone marrow (BM) smears, trephine biopsy giving special attention to the pattern and degree of infiltration by plasmacytic series. Detection of clonality of plasma cells by performing immunophenotyping on BM samples, serum protein and urine electrophoresis and immunofixation to detect the amount and type of paraproteins, and detection of Bence Jones protein (BJP) in fresh urine samples. Biochemical tests were used for detection of kidney function; serum creatinine, blood urea nitrogen (BUN), serum uric acid and serum, as well as measurement of prognostic variables; $\beta 2$-microglobulin $(\beta 2 \mathrm{M})$, serum albumin, lactate dehydrogenase (LDH) using Synchron CX9ALX (Beckman Coulter Electronics, Hialeah, FL, USA). C- reactive protein (CRP) was measured using semi quantitation Avitex CRP latex agglutination test (Omega Diagnostics Ltd, Hill foots Business village, Scotland, UK). Quantitative measurement of serum ICTP was performed by competitive binding enzyme linked immunosorbant assay (ELISA) technique using the human Ctelopeptide of collagen alpha-1 chain ELISA kit (EIAab, Wuhan EIAab Science Co., Ltd, Guanngguoji, East Lake Hi Tech Development Zone, China). The optical density of each well was obtained at wave length $450 \mathrm{~nm}$ using the microplate reader Stat fax 2100 (Fisher Bioblock Scientific SAS - Boulevard Sébastien Brant, France). Concentration of ICTP in the samples was obtained by comparing the optical density to a standard curve.

\section{Sample collection}

Blood samples were collected under complete aseptic conditions on ethylene diamine tetra-acetic acid (EDTA) $(1.2 \mathrm{mg} / \mathrm{mL})$ for $\mathrm{CBC}$ and preparation of PB smears. Part of serum obtained from clotted samples by centrifugation for $15 \mathrm{~min}$ at $1000 \mathrm{xg}$ was used for serum protein electrophoresis, immunofixation, CRP and biochemical analysis, the remaining serum was stored in aliquots at $-20{ }^{\circ} \mathrm{C}$ for measurement of ICTP. About $4 \mathrm{~mL}$ of $\mathrm{BM}$ aspirate were obtained to be used in performing smears, $2 \mathrm{~mL}$ were dispensed into vacutainer containing EDTA for immunophenotyping, and $2 \mathrm{~mL}$ were dispensed into vacutainer coated with heparin for cytogenetic analysis. Urine samples were collected for detection of BJP, urine protein electrophoresis and immunofixation.

\section{Diagnostic criteria}

The diagnosis of MM was based on the WHO diagnostic criteria $(2008)^{[12]}$; the presence of Mprotein in serum or urine, presence of bone marrow plasma cells or plasmacytoma and related organ or tissue impairments (CRAB: hypercalcemia, renal insufficiency, anemia and bone lesions).

\section{Group classification}

According to the results of radiological examination MM patients were classified at diagnosis into two groups; group A comprised 22 patients with osteolytic lesion and group B comprised $18 \mathrm{MM}$ patients without osteolytic lesion.

Patients were followed up for 18 months after initiation of treatment and, according to their treatment responses, they were classified into two groups responsive/stable group myeloma $(n=22)$ and relapsed/progressive group $(n=18)$. This classification was based on the International Myeloma Working Group Uniform Response Criteria (IMWG response criteria) ${ }^{[13]}$. Responsive disease included the following response categories; complete response (CR), stringent CR (sCR), very good partial remission (VGPR) and partial remission (PR). $\mathrm{CR}$ was defined as negative immunofixation on serum and urine, disappearance of any soft tissue plasmacytomas and $\leq 5 \%$ plasma cells in BM. $\mathrm{sCR}$ as $\mathrm{CR}$ plus normal free light chain ratio and absence of clonal plasma cells. VGPR was considered when serum and urine M-protein were detectable by immunofixation but not on electrophoresis or $90 \%$ or greater reduction in serum M-protein plus urine 
M-protein level <100 mg per 24 hours. PR was defined as a decrease in serum M-protein level $\geq 50 \%$ of the initial concentration and of M-protein in urine to $<200 \mathrm{mg}$ per 24 hours. A stable disease (SD) not meeting the criteria for CR, VGPR, PR or progression disease. A progressive disease required one or more of the following; increase of $\geq 25 \%$ from baseline in serum/urine $M$ component, BM plasma cell $\geq 10 \%$, development of new bone lesions or soft tissue plasmacytomas, increase in the size of existing bone lesions or soft tissue plasmacytomas, or development of hypercalcemia. Relapse after CR was considered when one or more of the following occurred; reappearance of serum/urine M-protein by immunofixation or electrophoresis, development of $\geq 5 \%$ plasma cells in BM, or appearance of any other sign of progression ${ }^{[13]}$. The clinical, laboratory and radiological data of all studied MM patients are listed in Table 1.

\section{Statistical analysis}

Data were analyzed using statistical program for Social Science (SPSS) version 18 IBM compatible PC. Quantitative data were described in the form of range and mean \pm standard deviation (SD) when the data were parametric and median with interquartile range (IQR) when the data were non parametric. Qualitative data were described in the form of number and percentage. Student t-test [Unpaired] was used to compare quantitative data between two groups when the data are parametric. Chi-square $\left(\mathrm{X}^{2}\right)$ was used to test the association of variables for categorical data. Fisher exact test was used instead of Chi-square test when the expected count in any cell was found less than 5 . Linear correlation coefficient (r) was used for detection of correlation between two quantitative variables in one group. Logistic regression was used to illustrate relationship between a dependent and one or more independent variables. Receiver Operating Characteristic curve (ROC) was used to illustrate the diagnostic properties of a test on a numerical scale. A $p$ value $<0.05$ was considered significant.

\section{Results}

Clinical, laboratory and prognostic data among MM patients with and without osteolytic lesions

As shown in Table 1, serum calcium, and creatinine were significantly higher among patients with osteolytic lesion $(\mathrm{p}=0.040, \mathrm{p}=0.045$, respectively), while no difference was found as regards demographic and clinical data, white blood cells (WBCs) count, hemoglobin concentration, platelet count, BM findings, presence of M-proteinemia or BJP ( $p>0.05)$.

The prognostic factors of MM; LDH, CRP and $\beta 2 \mathrm{M}$ were significantly higher in patients with osteolytic lesion $(p=0.036, p=0.003$ and $p=0.032$, respectively), while no significant difference was elicited between the two groups regarding serum albumin level ( $\mathrm{p}=0.512)$ (Table 1).

\section{Median ICTP levels among MM patients and controls}

The median [IQR] levels of ICTP were significantly higher in $\mathrm{MM}$ patients compared to the control group $(0.65[0.15-0.80] \mathrm{ng} / \mathrm{mL}$ versus 0.05 [0.04-0.07] ng/mL, $\mathrm{p}<0.001)$. Significant higher ICTP levels were detected among MM patients with osteolytic lesion (group A) compared with the patients without osteolytic lesion (group B) $(\mathrm{p}<0.001$; Table 1).

ROC curve analysis of the best ICTP cut off point for the diagnosis and prediction of the occurrence of osteolytic lesions in MM patients revealed that, the cut off value $0.3 \mathrm{ng} / \mathrm{mL}$ could differentiate between patients with and without osteolytic lesions with a sensitivity of $88.9 \%$, specificity of $100 \%$, positive predictive value of $100 \%$ and a negative predictive value of $91.7 \%$ and with accuracy of $95.5 \%$ (figure $1 \mathrm{~A}$ ).

Moreover, the results of this study revealed that two MM patients from group B, who had borderline elevated median ICTP levels at diagnosis $(0.3 \mathrm{ng} / \mathrm{mL}$ and $0.7 \mathrm{ng} / \mathrm{mL}$, respectively) developed bone lesion 6 months later during follow up. 
Relation between ICTP and the studied laboratory and radiological variables

ICTP levels in all studied MM patients were positively correlated with markers of renal impairment; serum BUN and serum creatinine levels $(r=0.767, p<0.001$ and $r=0.574, p=0.008$, respectively), and negatively correlated with hemoglobin, platelets count, and albumin level $(\mathrm{r}=-0.524, \mathrm{p}=0.018, \mathrm{r}=-0.525, \mathrm{p}=0.018$, and $\mathrm{r}=-$ 0.767, $\mathrm{p}=0.023$, respectively). Moreover, significant positive correlations were found between ICTP level and markers of osteolysis; serum $\mathrm{Ca}(\mathrm{r}=0.530, \mathrm{p}=0.016)$ and the standard prognostic variables of MM; LDH, CRP, and $\beta 2 \mathrm{M}$ $(\mathrm{r}=0.678, \mathrm{p}<0.001, \mathrm{r}=0.847, \mathrm{p}<0.001$, and $\mathrm{r}=0715$, $\mathrm{p}<0.001$, respectively). High ICTP levels were related to the presence of lytic lesion by radiological examination $(\mathrm{p}=0.001)$. No significant correlation was found between ICTP level and age, sex, WBCs, percentage of BM plasma cells, type of paraprotein or BJP ( $p>0.05)$. Similar results were found in group A myeloma patients when the relations between ICTP and

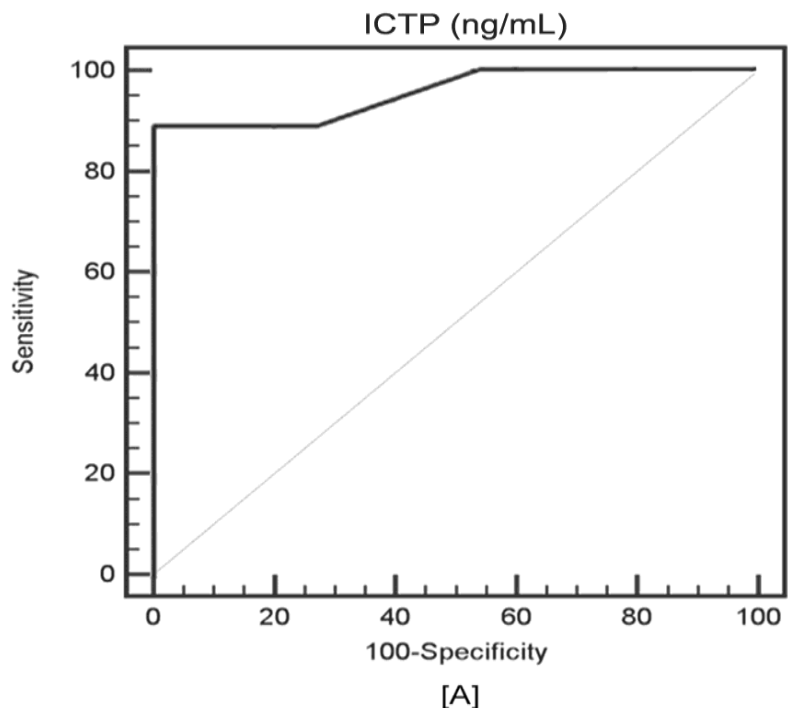

laboratory and radiological variables were assessed (figure 2).

Analysis of ICTP, $\beta 2 M$ and CRP as predictors of osteolysis

By using logistic regression analysis, we found that ICTP, $\beta 2 \mathrm{M}$ and CRP were significant predictors of osteolysis (Table 2). Upon comparison, ICTP was the most significant predictor of osteolytic changes in MM ( $\mathrm{p}=0.025)$.

\section{Relation between ICTP and response to treatment}

According to treatment response and follow-up of the studied MM patients, 22 patients had responsive/stable myeloma while 18 patients had progressive/relapsed disease. Baseline ICTP levels were significantly higher among the progressive/relapsed group of patients compared with the stable group, median [IQR] were $(0.90$ $[0.70-1.0] \mathrm{ng} / \mathrm{mL}$ versus $0.20[0.10-0.64]$ $\mathrm{ng} / \mathrm{mL} ; \mathrm{p}<0.001)$

ICTP $>0.65 \mathrm{ng} / \mathrm{mL}$ could predict poor response to treatment with a sensitivity of $88.9 \%$, specificity of $90.91 \%$, positive predictive value of $88.9 \%$ and a negative predictive value of $90.9 \%$ (figure $1 \mathrm{~B}$ ).

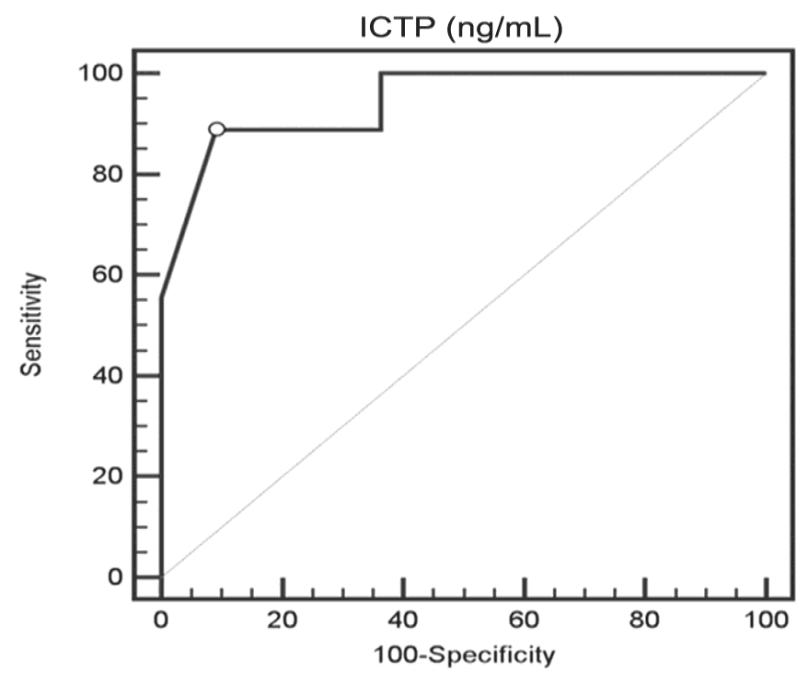

[B]

Figure 1: Receiver Operating Characteristic (ROC) curve analysis of [A] ICTP as a diagnostic marker of bone lesion in myeloma patients [B] ICTP as a predictor of progressive/relapsed disease in myeloma patients. 

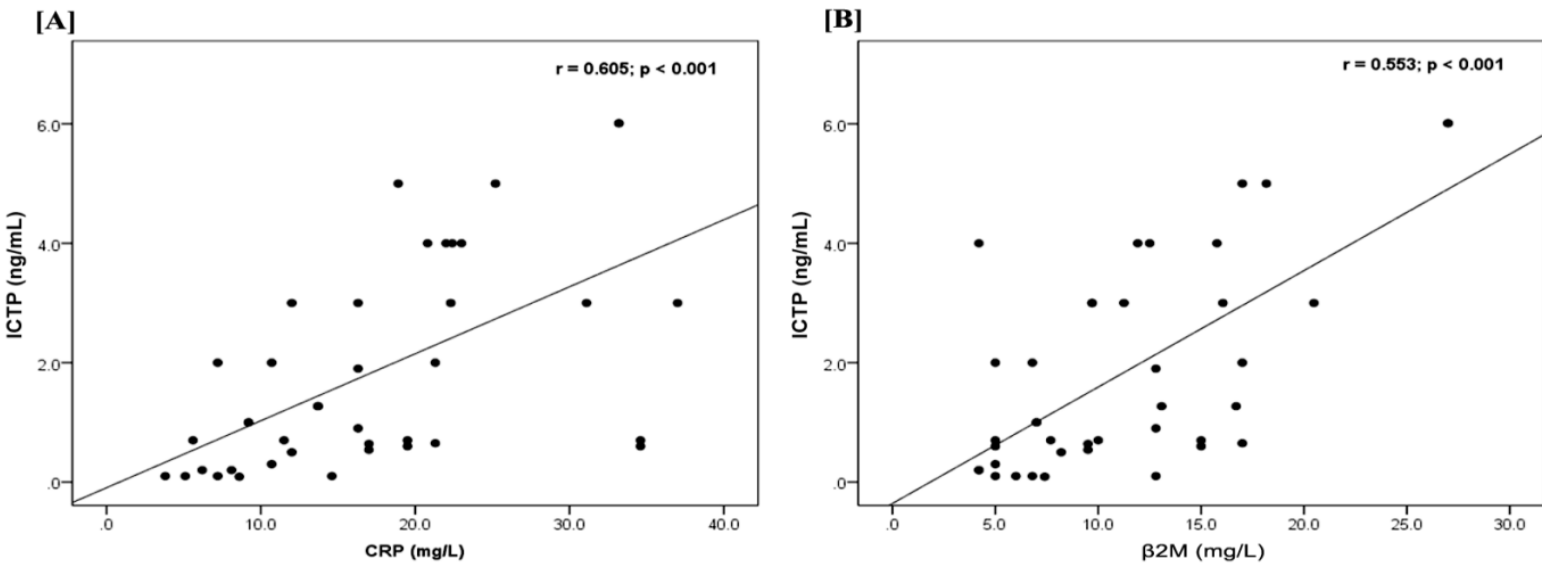

Figure 2: [A] Correlation between median ICTP levels and CRP in myeloma patients with osteolytic lesion. [B] Correlation between median ICTP level and $\beta 2 \mathrm{M}$ in myeloma patients with osteolytic lesion.

Table 1: Clinical, Laboratory and Radiological data of studied patients with multiple myeloma

\begin{tabular}{|c|c|c|c|c|}
\hline Variable & $\begin{array}{l}\text { All patients } \\
\mathrm{n}=40\end{array}$ & $\begin{array}{l}\text { Osteolytic lesion } \\
\text { (group A) } \\
n=22\end{array}$ & $\begin{array}{l}\text { No osteolytic lesion } \\
\text { (group B) } n=18\end{array}$ & $\begin{array}{l}\text { Group A } \\
\text { vs } \\
\text { group B } \\
\end{array}$ \\
\hline Age (years), mean \pm SD & $63.9 \pm 13.7$ & $63.1 \pm 13.7$ & $63.6 \pm 7.3$ & 0.928 \\
\hline Male, n (\%) & $24(60)$ & $12(54.55)$ & $12(66.7)$ & 0.097 \\
\hline Symptoms and signs of anemia, n (\%) & $36(90)$ & $20(90.9)$ & $16(88.9)$ & 0.989 \\
\hline Bone aches, n (\%) & $34(85)$ & $20(90.9)$ & $14(77.8)$ & 0.715 \\
\hline Osteolytic lesion by radiology, n (\%) & $22(55)$ & $22(100)$ & $0(0)$ & $<0.0001$ \\
\hline WBCs $\left(\times 10^{9} / \mathrm{L}\right)$ & $9.1 \pm 4.9$ & $7.2 \pm 2.8$ & $11.4 \pm 6$ & 0.053 \\
\hline $\mathrm{Hb}(\mathrm{g} / \mathrm{dL})$ & $8.4 \pm 1.4$ & $8.2 \pm 1.6$ & $8.6 \pm 1.1$ & 0.535 \\
\hline Platelet $\left(\mathrm{x} 10^{9} / \mathrm{L}\right)$ & $173 \pm 53.4$ & $71.6 \pm 24.3$ & $51.6 \pm 36.4$ & 0.416 \\
\hline BM plasma cells $(\%)$, mean \pm SD & $39.2 \pm 21.2$ & $41.6 \pm 18.6$ & $36.3 \pm 24.8$ & 0.589 \\
\hline \multicolumn{5}{|l|}{$\begin{array}{l}\text { BM trephine biopsy, n (\%) } \\
\text { Cellularity }\end{array}$} \\
\hline Hypercellular & $16(40)$ & $12(54.55)$ & $4(22.2)$ & 0.340 \\
\hline Normocellular & $22(55)$ & $10(45.5)$ & $12(66.7)$ & 0.637 \\
\hline Hypocellular & $2(5)$ & $0(0)$ & $2(11.1)$ & 0.650 \\
\hline \multicolumn{5}{|l|}{ Infiltration pattern } \\
\hline Patchy & $8(20)$ & $4(18.2)$ & $4(22.2)$ & 0.974 \\
\hline Diffuse & $16(40)$ & $12(54.5)$ & $4(22.2)$ & 0.340 \\
\hline Interstitial & $16(40)$ & $14(63.6)$ & $2(11.1)$ & 0.058 \\
\hline Type of monoclonal protein by IFE, n (\%) & & & & \\
\hline $\operatorname{Ig} A \lambda$ & $10(25)$ & $6(27.3)$ & $4(22.2)$ & 0.967 \\
\hline $\operatorname{IgG} \lambda$ & $14(35)$ & $10(45.5)$ & $4(22.2)$ & 0.555 \\
\hline $\operatorname{Ig} \mathrm{A}_{\mathrm{K}}$ & $8(20)$ & $4(18.2)$ & $4(22.2)$ & 0.974 \\
\hline $\operatorname{IgG} \mathrm{K}$ & $8(20)$ & $2(9.1)$ & $6(33.3)$ & 0.974 \\
\hline BJP, n (\%) & $12(30)$ & $10(45.5)$ & $2(11.1)$ & 0.095 \\
\hline Creatinine $(\mathrm{mg} / \mathrm{dL})$, mean $\pm \mathrm{SD}$ & $3.81 \pm 2.02$ & $4.62 \pm 1.8$ & $2.8 \pm 1.9$ & 0.045 \\
\hline BUN (mg/dL), mean \pm SD & $42.6 \pm 32.9$ & $52.6 \pm 41.9$ & $30.6 \pm 9.2$ & 0.143 \\
\hline Uric acid $(\mathrm{mg} / \mathrm{dL})$, mean $\pm \mathrm{SD}$ & $7 \pm 1.7$ & $7.2 \pm 1.8$ & $6.8 \pm 1.7$ & 0.602 \\
\hline Albumin $(\mathrm{g} / \mathrm{dL})$, mean $\pm \mathrm{SD}$ & $2.1 \pm 0.58$ & $2.2 \pm 0.7$ & $2.02 \pm 0.44$ & 0.512 \\
\hline $\mathrm{Ca}(\mathrm{mg} / \mathrm{dL})$, mean $\pm \mathrm{SD}$ & $9.8 \pm 1.8$ & $10.5 \pm 1.4$ & $8.9 \pm 1.8$ & 0.040 \\
\hline LDH (IU/L), mean \pm SD & $559 \pm 253.7$ & $665.4 \pm 256.7$ & $430 \pm 190.7$ & 0.036 \\
\hline $\mathrm{CRP}(\mathrm{mg} / \mathrm{L})$ & $14 \pm 7.3$ & $19.6 \pm 10.5$ & $8.4 \pm 3.4$ & 0.003 \\
\hline$\beta 2 \mathrm{M}(\mathrm{mg} / \mathrm{L})$ & $9.7 \pm 5.8$ & $12.1 \pm 6.6$ & $6.8 \pm 2.9$ & 0.039 \\
\hline ICTP (ng/mL), median (IQR) & $0.65(0.15-0.80)$ & $0.70(0.65-1.0)$ & $0.10(0.10-0.20)$ & $<0.001$ \\
\hline
\end{tabular}

WBCs: white blood cells count, Hb: hemoglobin, BM: bone marrow, IFE: immunofixation electrophoresis, BJP: Bence Jones protein, BUN: blood urea nitrogen, Ca: calcium, LDH: lactate dehydrogenase, CRP: Creactive protein, $\beta 2 \mathrm{M}$ : beta 2 microglobulin, ICTP: collagen type 1 carboxy terminal telopeptide.

Data were expressed as mean \pm SD where Student $t$ test used or as median using Mann Whitney test for comparison unless specified as number (percentage) using Chi- square $\left(\mathrm{X}^{2}\right)$ test for comparison. 
Table 2: Logistic regression analysis of ICTP, $\beta 2 \mathrm{M}$ and CRP as osteolytic predictors

\begin{tabular}{|l|l|l|l|l|}
\hline \multirow{2}{*}{} & \multicolumn{2}{|l|}{$\begin{array}{l}\text { Unstandardized } \\
\text { Coefficients }\end{array}$} & $\begin{array}{l}\text { Standardized } \\
\text { Coefficients }\end{array}$ & p-value \\
\cline { 2 - 5 } & $\mathrm{B}$ & Standard Error & Beta & 0.041 \\
\hline$($ Constant $)$ & -2.657 & 1.164 & & 0.025 \\
\hline $\mathrm{ICTP}(\mathrm{ng} / \mathrm{mL})$ & -0.160 & 0.156 & -0.428 & 0.048 \\
\hline $\mathrm{CRP}(\mathrm{mg} / \mathrm{L})$ & 0.030 & 0.019 & 0.543 & 0.040 \\
\hline$\beta_{2} \mathrm{M}(\mathrm{mg} / \mathrm{L})$ & 0.169 & 0.074 & 0.533 & \\
\hline Dependent Variable: X-ray & & & & \\
\hline
\end{tabular}

ICTP: collagen type 1 carboxy terminal telopeptide, CRP: C-reactive protein, $\beta 2 \mathrm{M}$ : beta 2 microglobulin.

\section{Discussion}

In this study, the osteolytic marker ICTP was significantly elevated among $\mathrm{MM}$ patients compared to the controls with significant elevation among MM patients with osteolytic lesion compared with patients without osteolysis. Similar results were found by other studies [13,14,15], suggesting that the degradation product of collagen type I carboxy terminal telopeptide (ICTP) reflects osteoclast activity and appears to be a useful marker for skeletal resorptive and degradation processes in patients with $\mathrm{MM}$ $[16,17,18]$. Results of the current study showed that ICTP level of $3 \mathrm{ng} / \mathrm{mL}$ could be considered diagnostic of osteolytic changes in MM patients with high sensitivity and specificity.

Moreover, results of the present study determined that ICTP, $\beta 2 \mathrm{M}$, CRP are significant predictors of osteolysis, with ICTP being the most significant predictor of osteolytic changes. Two MM patients without oseolytic lesion by radiology who had elevated ICTP level at diagnosis, developed lytic lesions later on during the follow up period. Jakob et al. ${ }^{[17]}$ demonstrated that serum ICTP was elevated in MM patients who did not have detectable osteolytic lesions by plain radiograph, but had abnormal bone magnetic resonance imaging scans. This may be explained by the very early on-going osteolysis before symptomatic or even diagnostic radiological disease evidence, valuing the ICTP testing at diagnosis, as a predictor marker of osteolysis and may be the importance of starting therapy even with normal radiography.

Our results revealed that ICTP levels were positively correlated with markers of renal impairment. ICTP is cleared through the kidneys, and impaired glomerular filtration has been shown to lead to increases in serum telopeptides ${ }^{[19]}$.

ICTP levels were positively correlated with anemia and thrombocytopenia as well as with the standard $\mathrm{MM}$ risk factors; $\beta 2 \mathrm{M}, \mathrm{CRP}$, albumin, $\mathrm{LDH}$ and markers of bone resorption; hypercalcemia and radiological data. All these findings may imply that serum ICTP could reflect disease severity and poor prognosis among MM patients.

In order to find a relation between baseline ICTP level and disease progression or response to treatment according to the response criteria defined by IMWG ${ }^{[13]}$, patients were followed up for 18 months to detect their treatment response. We found that baseline ICTP levels were significantly lower in responsive/stable myeloma patients compared with the progressive/relapsed group. ICTP level > $0.65 \mathrm{ng} / \mathrm{mL}$ could predict poor response to therapy with high sensitivity and specificity.

Bačovský J et al. ${ }^{[20]}$ detected increasing ICTP levels in $\mathrm{MM}$ patients with progressive or relapsing disease in their study of $73 \mathrm{MM}$ patients over a period of three years. Moreover, Abildgaard et al. [21] performed sequential measurements of both ICTP and amino-terminal cross-linking telopeptide of type I collagen (NTX) 
and showed that high levels of ICTP and NTX correlated with an increased risk for early progression of bone lesions during conventional chemotherapy, suggesting that their measurements may be clinically useful for identifying patients with increased risk of early disease progression.

In conclusion, ICTP is a reliable and sensitive bone resorption marker that can be used in diagnosis and prediction of development of osteolytic bone lesion as well as prediction of response of MM patients to treatment. We recommend that patients with high levels of ICTP should be managed with the same intensive treatment approach reserved for high-risk MM patient groups, even in the absence of osteolytic lesions on conventional radiography. Further longitudinal studies including larger number of patients with extended follow-up may provide additional information.

Conflict of Interest Statement: Nothing to declare.

\section{Reference}

1. Turesson I, Velez R, Kristinsson SY, Landgren O. Pattern of MM during the last 5 decades: stable incidence rates for all groups in the population but rapidly changing age distribution in the clinic. Mayo Clinic Proceedings. 2010;85:225230.

2. Palumbo A, Kenneth Anderson. Multiple Myeloma. N Engl J Med. 2011;364:10461060.

3. Dimopoulos MA, Terpos E. Renal insufficiency and failure. Hematology Am Soc Hematol Educ Program 2010; 2010: 431-436.

4. Hinge M, Lund T, Delaisse J, Plesner T. Bone disease in Multiple Myeloma. INTECH Open Access Publisher, 2013.

5. San-Miguel J, Bladé J. Multiple Myeloma. In: Hoffbrand AV, Catovsky D, Tuddenham E, Green A (eds). Post Graduate Hematology. $6^{\text {th }}$ edn. NJ, USA:
Blackwell Publishing Ltd;2011,pp:577597.

6. Abildgaard N, Glerup H, Rungby J, dixHansen K, Kassem M, Brixen K. Biochemical markers of bone metabolism reflect osteoclastic and osteoblastic activity in multiple myeloma. Eur $\mathbf{J}$ Hematol 2010;84:412-420.

7. Lombardi G, Lanteri P, Colombini A, Banfi G. Blood biochemical markers of bone turnover: Pre- analytical and technical aspects of sample collection and handling. Clin Chem Lab Med.2012; 50:771-789.

8. Gordon MK, Hahn RA. Collagens. Cell Tissue Res 2010; 339:247-257.

9. Chopin F, Biver E, Funck-Brentano T, Bouvard B, Coiffier G, Garnero P, Thomas T. Prognostic interest of bone turnover markers in the management of postmenopausal osteoporosis. Joint Bone Spine.2012;79:26-31.

10. Tezvergil A, Mutluay M, Seseogullari R, Agee K, Key W, Scheffel D, et al. Effect of phosphoric acid on the degradation of human dentin matrix. J Dent Res 2013;92: 87-91.

11. Torres P. Biological parameters for the diagnosis of bone turnover in dialysis patient. Nephrology and Clinical Chemistry: The Essential Link. 2012:106121.

12. McKenna RW, Kyle RA, Kuehi WM, Grogan TM, Harris NL, Coupland RW. Plasma cell myeloma In: Steven HS, Campo E, Harris NL, Jaffe ES, Pileri SA, Stein H, Thiele J, Vardiman JW (eds). WHO Classification of tumours of hematology and lymphoid tissues. $4^{\text {th }}$ edn. Lyon, France:International agency for research on cancer (IARC) 2008, 200-213.

13. Kyle R, Rajkumar S. Criteria for diagnosis, staging, risk stratification and response assessment of multiple myeloma. Leukemia: official journal of the 
Leukemia Society of America, Leukemia Research Fund, UK. 2009;23(1):3-9.

14. Djunic I, Elezovic I, Marinkovic M, Suvajdzic-Vukovic N, Tomin D, Jankovic $\mathrm{G}$, et al. Osteolytic lesions marker in multiple myeloma. Med Oncol.2011;28:237-240.

15. Kuliszkiewicz-Janus M, Malecki R, Zóltaszek A, Zastawny M. The significance of carboxy-terminal telopeptide of type I collagen (ICTP) and osteocalcin (OC) in assessment of bone disease in patients with multiple myeloma. Leuk Lymphoma 2005; 46:1749-1753.

16. Terpos E, Szydlo R, Apperley JF, Hatjiharissi E, Politou M, Meletis J, et al. Soluble receptor activator of nuclear factor $\kappa \mathrm{B}$ ligand osteoprotegerin ratio predicts survival in multiple myeloma: proposal for a novel prognostic index. Blood 2003;102:1064-1069.

17. Jakob C, Zavirski I, Heider U, Bollow M, Schulz CO, Fleissner C, et al. Serum levels of carboxyterminal telopeptide of type-I collagen are elevated in patients with multiple myeloma showing skeletal manifestations in magnetic resonance imaging but lacking lytic bone lesions in conventional radiography. Clin Cancer Res. 2003;9:3047-3051.

18. Batallie R, Chappard D, Marcelli C, Rossi JF, Dessauw P, Baldet P, et al. Osteoblast stimulation in multiple myeloma lacking lytic bone lesions. $\mathrm{Br} \quad \mathrm{J}$ Haematol.1990;76:484-487.

19. Abilgaard N, Glerup H, Rungby J, BendixHansen K, Kassem M, Brixen $\mathrm{K}$ et al. Biochemical markers of bone metabolism reflect osteoclastic and osteoblastic activity in multiple myeloma. Eur $\mathbf{J}$ Haematol. 2000;64:124-129.
20. Bačovský J, Ščudla V, Vytřasová M, Budíková M, Mysliveček M. Monitoring of bone resorption and bone formation in multiple myeloma. Biomed Paper.2002;146:59-61.

21. Abildgaard N, Brixen K, Eriksen EF, Kristensen JE, Nielsen JL, Heickendorff L. Sequential analysis of biochemical markers of bone resorption and bone densitometry in multiple myeloma. Haematologica 2004;89:567-577. 